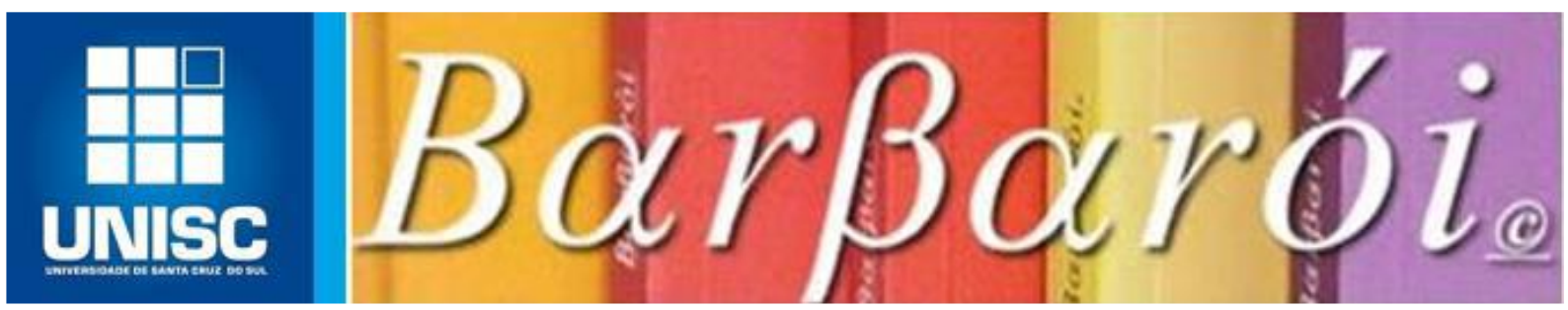

\title{
O ASSISTENTE SOCIAL E O ATENDIMENTO DE MULHERES VÍTIMAS DE VIOLÊNCIA DOMÉSTICA E FAMILIAR
}

\author{
DOI: http://dx.doi.org/10.17058/barbaroi.v0i0.14876

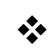

\author{
Allan Jones Andreza Silva \\ Polícia Militar da Paraíba - PMPB - Brasil \\ Daniele de Araújo Nogueira \\ Universidade Norte do Paraná - UNOPAR - Brasil
}

$\bullet$

\section{Resumo}

Este trabalho trata sobre a violência doméstica e familiar contra a mulher, partindo do questionamento sobre como deve atuar o assistente social frente às ocorrências desta natureza. Como objetivos específicos tem-se a apreciação da complexidade e características da temática e a verificação da importância deste profissional nestes tipos de casos. Sob o ponto de vista metodológico utilizou-se as técnicas de pesquisa documental e bibliográfica, como instrumentos hábeis para possibilitar uma abordagem dedutiva, ocasião na qual a revisão bibliográfica coligida deve subsidiar as análises para estipular as condições de exercício do profissional de assistência social diante do problema tratado. Diante do precário conhecimento sobre as vicissitudes da violência doméstica, muitas vítimas têm dificuldades para reconhecer sua vitimização, ocasionando deficiência na detecção pelos profissionais envolvidos no atendimento (policiais, médicos etc.), o que apenas pode ser suprido pela escuta qualificada e intervenção do assistente social, através da orientação sobre direitos e garantias assecuratórias da integridade física, psicológica, patrimonial, moral e sexual da mulher em estado de vulnerabilidade, articulação da rede de atendimento e devidos encaminhamentos.

Palavras-Chave: Mulher. Violência. Assistente Social. Direitos.

\section{Introdução}

Apesar da proteção de uma vasto rol de direitos, dentre os quais a segurança pública, a igualdade, a vida, integridade física, ter sido uma das grandes conquistas e destaque da Constituição de 1988, também chamada de "Constituição Cidadã", mesmo assim, paradoxalmente, muitas mulheres são vitimadas diariamente, constituindo uma fórmula de violação de direitos que é tão recorrente que algumas vezes chega a ser observada com apatia por muitas pessoas, dentre as quais não apenas os agressores (que veem isso como exercício do 
seu poder ou de sua autoridade sob a mulher), mas até, em muitos casos, pelas próprias vítimas que já tem incorporado esta submissão como papel social feminino e suportam tais violências em silêncio.

Em pesquisa conjunta sobre a incidência desta forma de violência, a Instituto de Pesquisa Econômica Aplicada (IPEA) e o Fórum Brasileiro de Segurança Pública (FBSP) (2019) apontaram que o Brasil vivencia um ritmo crescente de homicídios de mulheres ao longo do tempo, de maneira que "entre 2007 e 2017 houve aumento de 20,7\% na taxa nacional de homicídios de mulheres, quando a mesma passou de 3,9 para 4,7 mulheres assassinadas por grupo de 100 mil mulheres" (p. 35). A referida pesquisa ainda apontou que no Brasil em 2017, foram assassinadas 4.936 mulheres, correspondendo a uma média de 13 vitimizações por dia (IPEA; FBSP, 2019, p. 35). ${ }^{1}$.

A vitimização das mulheres nas relações domésticas, essencialmente por seus parceiros, demonstra a desestabilização na formulação estrutural das condições de paridade familiar entre mulheres e homens, sedimentada em práticas de discriminação e subordinação do gênero feminino.

Dentre as dificuldades encontradas para o enfrentamento do problema está a carência de denúncias e notificações aos órgãos estatais sobre tal violência, seja por passividade ou precariedade de conhecimento da mulher ou dos seus familiares sobre os direitos a ela assistidos, além do despreparo de muitos setores da administração pública para lidar com as vítimas sendo, portanto, necessário refletir sobre uma adequada atuação para a garantia e proteção dos direitos da mulher. Acrescente-se ainda que, em muitos casos, a dependência econômica e emocional, vergonha e falta de apoio familiar são apenas alguns dos fatores que favorecem o silêncio das vítimas, desta maneira o conhecimento sobre as vicissitudes da temática pelo assistente social é imprescindível para romper as barreiras que impõe o sigilo da vitimização, passo essencial para a garantia da dignidade feminina.

Neste contexto, compreende-se nem sempre os profissionais de saúde, de segurança pública e outros servidores públicos envolvidos no atendimento às mulheres conseguem detectar a vitimização e, por conseguinte, proporcionar as condições adequadas para minimizar os sofrimentos femininos, o que apenas é possível através de uma escuta sensível, atenta as vicissitudes do problema. Neste interim, a atuação do assistente social acaba sendo primordial,

\footnotetext{
${ }^{1}$ Segundo a pesquisa elaborada pelo Fórum Brasileiro de Segurança Pública e Datafolha (2019), 16 milhões de mulheres com 16 anos ou mais, ou seja 16 milhões delas, sofreram algum tipo de violência nos últimos 12 meses da elaboração da pesquisa, o que, por si só, denota uma incidência alarmante, entretanto 52\% delas não adotaram nenhuma providência imediata, não acionaram qualquer órgão (Polícia Civil, Polícia Militar, Disque 180 etc.).
}

Barbarói, Santa Cruz do Sul, n. 56, p.<44-67>, jan./jun. 2020 
pois além de atentar as condições sociopsicológicas da vítima, desempenha função essencial para assegurar seus direitos fundamentais, desde a garantia da informação, a partir do processo de orientação quanto aos seus direitos, medidas protetivas e políticas ou programas sociais que lhes são ofertados para garantia de sua proteção física, psicológica, patrimonial, moral e sexual, até mesmo mediante os encaminhamentos necessários para os órgãos pertencentes a rede de atendimento à mulher em situação de vulnerabilidade.

Deste modo, constata-se que o presente trabalho versa sobre o papel do Assistente Social frente os casos de vitimização de mulheres por violência doméstica e familiar. A relevância da referida pesquisa se justifica pela complexidade do tema que extrapola a ceara criminal, causando reflexos evidentes em âmbito social, econômico, jurídico, de saúde pública etc.

O trato sobre o tema merece atenção, principalmente por duas razões específicas: sua singularidade frente as demais manifestações de violência e, em segundo lugar, pela complexidade do seu atendimento, onde a detecção desta forma de vitimização nem sempre é uma circunstância fácil de ser realizada, sobretudo em decorrência da perceptível naturalidade que, muitas vezes, esta circunstância é encarada pela própria vítima e seus familiares, o que, por conseguinte, acaba necessitando de uma atuação perspicaz do assistente social.

O problema que norteia a pesquisa é: como o profissional de serviço social deve atuar para melhor garantir a dignidade das mulheres em situação de violência? A reflexão sobre esse questionamento é tratado como objetivo geral do presente trabalho, que ao mesmo tempo aborda esta temática a partir das seguintes perspectivas específicas: a) verificação dos múltiplos fatores que influenciam a vitimização das mulheres em âmbito doméstico e familiar (em seus aspectos social, econômico, cultural, criminológico, entre outros); b) análise das possíveis fórmulas de atendimento do Assistente Social às mulheres vitimadas.

Desta maneira, para atender tais objetivos, geral e específicos, esta pesquisa é pautada num processo metodológico sedimentado na problematização do papel do assistente social, oportunidade na qual a função social deste profissional é enfatizada frente a questão da violência doméstica e familiar, como fórmula necessária para desmistificar estereótipos e proporcionar o devido reconhecimento e relevância que este exerce para a garantia e promoção dos direitos fundamentais da mulher em situação de vulnerabilidade.

\subsection{Metodologia aplicada}

O presente trabalho parte de uma pesquisa pautada num processo metodológico sedimentado na aplicação de três matrizes: a primeira, de caráter sociológico, busca compreender as vicissitudes da violência doméstica e familiar contra a mulher; a segunda, de 
natureza jurídica, trata de discutir os mecanismos legais de enfrentamento deste tido de violência; a terceira, e última trata de analisar o papel do assistente social frente às peculiaridades da vitimização feminina.

Portanto, o trabalho proposto explora o objeto (o atendimento de mulheres vítimas de violência doméstica) pela interposição de uma união metodológica científica, transdisciplinar, mas desenvolvida pela ótica sociológica e jurídica para compreender o papel e os vieses de enfretamento da questão pelo assistente social.

Para o desenvolvimento do trabalho, seguindo a classificação de Marconi e Lakatos (2003), fora adotada uma abordagem metodológica dedutiva, oportunidade na qual a revisão bibliográfica coligida sobre a violência doméstica e os aspectos jurídicos relacionados a questão subsidiam a compreensão e o balizamento cognoscível das condições de intervenção do profissional de assistência social perante o problema tratado, assim parte-se do trato sobre esta violência para, de maneira específica, identificar as estratégias de atuação do assistente social.

Ainda de acordo com Marconi e Lakatos (2003), será utilizada a técnica de pesquisa bibliográfica sobretudo de cunho sociológico, jurídicos e ainda utilizada alguns referenciais da literatura feminista e especializada sobre a violência doméstica, não obstante ainda será utilizada a pesquisa documental, especificamente relacionada às principais legislações e dados que versem sobre o objeto de estudo (como, por exemplo a Lei $n^{\circ} 11.340 / 2006$, Lei $n^{\circ}$ 13.641/2018, Lei n ${ }^{\circ} 8662 / 1993$, dentre outros).

As informações coligidas pela pesquisa subsidiam a formulação dos três capítulos subsequentes: o primeiro, trata sobre a violência contra a mulher, enfatizando sua significação e as medidas interventivas; o segundo, versa sobre as questões jurídicas atreladas a questão; e o terceiro e último, a atuação do assistente social frente as demandas desta natureza.

\section{Violência contra mulher: significações e medidas interventivas}

A violência doméstica e familiar contra a mulher pode tratar-se não apenas de um ato de agressão explícito, mas também pode versar sobre algo implícito nas relações de gênero, uma tácita imposição baseada nos atributos sexuais. Partindo destas considerações, é importante verificar que para o Ministério da Saúde (BRASIL, 2005, p. 118), gênero diz respeito “(...) a relações de poder e à distinção entre atributos culturais atribuídos a cada um dos sexos e suas peculiaridades biológicas".

Assim, ao tratar do assunto é necessário atentar a duas premissas fundamentais, como bem observa Gomes (2008, p. 238), o gênero é elemento basilar para compreensão das diferenças nas relações sociais percebidas entre os sexos e, ao mesmo tempo, constitui o Barbarói, Santa Cruz do Sul, n. 56, p.<44-67>, jan./jun. 2020 
primeiro campo de articulação do poder.

Percebe-se a partir de então que as concepções de gênero não são fundadas propriamente na anatomia fisiológica dos indivíduos, mas sim no papel social que exercem a partir de padrões de comportamento historicamente definidos, ou seja, não são baseados em papéis ofertados ao indivíduo, mas sim impostos pela sociedade como característica atrelada a sua fisionomia biológica, vindo a constituir desde logo cedo um elemento intrínseco a sua identidade social (vestes, comportamentos, atividades, gestos etc.) (BOURDIEU, 2000).

Na maioria dos casos, por se tratar de algo muitas vezes imposto e não individualmente optado, as relações de gênero também demonstram condições de subordinação e hierarquização entre pessoas de sexos diferentes, sobreposição de interesses e violência. Sobre este contexto, Souza (2009, p. 35) informa:

\begin{abstract}
Essa cultura de diferença de Gênero ganhou força, ao longo do tempo, através da prática de impor a homens e mulheres papéis sociais determinados, impondo a eles, desde o nascimento, uma espécie de "camisa" com regras que devem ser "vestidas" ou observadas, tais quais a de que ao homem cabe ser forte, decidido, empreendedor, líder etc., sugerindo, ao contrário, a incapacidade da mulher pra exercer as funções que exigem os atributos exigidos ao gênero masculino e, por conseguinte, a inferioridade do Gênero feminino, por si só submisso, num processo semelhante ao que norteou a relação social dos homens livres com os escravos, no período da escravidão.
\end{abstract}

Ainda para Souza $(2009$, p. 27), apesar de haver uma estreita vinculação entre a violência de gênero, a violência contra as mulheres e a violência doméstica, são conceitualmente distintas. Convém esclarecer que a violência de gênero diz respeito às violações de direitos considerando a participação social da mulher, suas relações de trabalho e de subordinação. Esta é uma condição essencialmente antiga e culturalmente aceita segundo as ações sociais. Já a violência contra a mulher enfatiza a vitimização baseada no sexo biológico, enquanto que a violência doméstica é uma prática não necessariamente dirigida apenas a mulher, mas que detém um ambiente específico de efetivação que é a o âmbito doméstico.

Mesmo assim, pode-se considerar que a violência doméstica e familiar contra mulher é episódio social e juridicamente reprovável, mas que constitui o amalgama resultante de relações de opressão e dominação masculina, até mesmo como medida de afirmação do poder do homem sobre a mulher, com múltiplas significações e influências sob sua vida, seja de caráter público, seja, principalmente, no ambiente privado.

Ademais, é importante verificar que o próprio termo "violência", carrega consigo certa complexidade semântica, conceitual e prática, constituindo um importante alvo de reflexão para compreensão da individualização de sua manifestação fática, sua heterogeneidade, imprevisibilidade episódica, o animus motivacional subjetivo, os influxos da interação 
interpessoal e/ou coletiva que o ocasionam e seus efeitos produzidos.

\subsection{A violência doméstica e familiar contra a mulher}

A formulação de uma nova condição social da mulher, que inicia com a sua participação ativa no mercado de trabalho e economia familiar, acaba por conclamar a intensificação dos debates quanto da proteção dos direitos femininos, os quais ganham impulso após a ratificação dos tratados internacionais sobre direitos humanos da mulher.

Especificamente no Brasil, a temática violência contra as mulheres começou a ser discutida de forma mais intensa a partir dos anos 1980, graças às transformações sociais e políticas que deram voz aos movimentos feministas, os quais ansiavam por medidas legislativas de prevenção e sancionatórias aos agressores².

É necessário observar que já estava em desenvolvimento um pensamento jurídico que identificava como medida plausível a intervenção penal como medida voltada para o desestímulo ou prevenção de prejuízos a bens jurídicos relevantes para a proteção dos direitos do cidadão.

Neste contexto, é necessário observar as palavras de Guimarães:

(...) os Estados democráticos ou que se democratizaram ao longo da terceira onda constitucional, arrimam-se no modelo político-jurídico-econômico do welfare state, confirmando os espaços de liberdade negativa, dos direitos e garantias fundamentais e estabelecendo direitos fundamentais e normas programáticas que se efetivam pela intervenção estatal, visando o aperfeiçoamento individual e coletivo da sociedade. Quer dizer, há suficiente legitimação político-jurídica para a criação não só de um direito que tenha promoção das pessoas, como também para a tutela de bens jurídicos através da intervenção penal e do processo (GUIMARÃES, 2011, p. 65).

A implementação de mecanismos verdadeiramente mais evidentes de proteção do direito das mulheres aconteceu com a promulgação da Constituição Federal de 1988, a qual foi capaz de recepcionar uma série de normas dirigidas a proteção da mulher, além do próprio texto magno informar expressamente o direito à igualdade de sexos. Mesmo assim, de forma ainda contraditória, esta mesma constituição recepcionou muitas normas que comprometiam a formulação da igualdade legal entre os gêneros, pois estipulavam desníveis nas relações sociais, além do mais o conjunto normativo que se estabeleceu logo após a promulgação do texto magno acabou enfrentando sérias dificuldades para garantir os direitos da mulher, sobretudo no que concerne a sua não vitimização em ambiente doméstico.

\footnotetext{
2 "Nesse período, o movimento de mulheres tinha como um dos principais objetivos dar visibilidade à violência contra a mulher e tentar combatê-la por meio de intervenções sociais e jurídicas, mormente, a criminalização de condutas. Incentivado pela redemocratização política que dava seus primeiros passos na sociedade brasileira, o movimento de mulheres iniciou um diálogo com o Estado, no sentido de reivindicar políticas que dessem respostas institucionais de prevenção e punição da violência praticada contra a mulher" (CELMER, 2010, p. 76).
}

Barbarói, Santa Cruz do Sul, n. 56, p.<44-67>,jan./jun. 2020 
Dentre os problemas, conforme relatam Day et al (2003, p. 15), verifica-se a dificuldade do Estado adentrar no campo das relações privadas domésticas, uma vez que a violência contra mulher é realizada mais comumente por pessoas próximas, geralmente parentes ou parceiros íntimos, seguindo um padrão repetitivo, de controle e de dominação, desenvolvido em ambiente residencial (dentro do lar), longe dos olhos estatais, o que faz das propostas dirigidas a minimização do problema uma tarefa extremamente difícil e delicada, principalmente para os órgãos encarregados diretamente pela segurança pública, as polícias.

A violência doméstica e familiar contra mulher conceitualmente está relacionada as medidas de cunho comissivo ou omissivo direcionadas para causar prejuízos diretos a integridade física e psicológica, a moral, o patrimônio e a liberdade sexual da mulher, onde o agressor se prevalece da relação de afeto, decorrente da convivência no lar para executar tal violação. Por conseguinte, é importante destacar que o conceito jurídico está insculpido no art. $5^{\circ}$ da Lei 11.340/2006, como: “(...) qualquer ação ou omissão baseada no gênero que lhe cause morte, lesão, sofrimento físico, sexual ou psicológico e dano moral ou patrimonial", no âmbito da unidade doméstica, familiar ou em qualquer relação íntima de afeto, na qual o agressor conviva ou tenha convivido com a ofendida independentemente de coabitação ${ }^{3}$.

Desta maneira, a violência doméstica diferencia-se das demais por enfatizar o aspecto espacial, ou seja, o ambiente do lar, consequentemente, o sujeito passivo mais comum, a mulher, tem seus suplícios inauditos por ser vitimada entre quatro paredes, na maioria dos casos longe dos olhares estatais e ainda assim minimizados sob a ótica machista de parentes, vizinhos e amigos.

No que diz respeito às motivações, Day el tal (2003, pp. 15-16) destacam que elas estão relacionadas às características pessoais do agressor, os riscos na relação e a sociedade. No que diz respeito ao agressor é evidenciado que as suas condições psicossociais têm estreita relação com a reprodução de práticas violentas, tomando como causa: o pensamento machista, já ter presenciado conflitos conjugais dos seus pais, experiências de abuso ainda quando criança, o consumo de bebidas, riscos na relação interpessoal (conflitos) e, dentre outros, o apoio simbólico da comunidade.

Atreladas a estas condições, alguns outros fatores decorrentes das relações econômicosociais, como controle das riquezas e tomadas de decisões elevam ainda mais a possibilidade de desenvolvimento de práticas violentas nas relações domésticas e familiares, seja para

\footnotetext{
3“Nesse extenso âmbito enquadra-se as mulheres que se encontrem no âmbito doméstico, mesmo que não tenham vínculo familiar com o agressor, como ocorre na relação entre empregados doméstico e entre eles e os moradores da residência, quando haja uma razoável estabilidade nessa relação" (SOUZA, 2009, p. 41).
}

Barbarói, Santa Cruz do Sul, n. 56, p.<44-67>, jan./jun. 2020 
consolidar a condição de superioridade pela reafirmação do poder (por exemplo, o homem que utiliza o seu poder econômico para oprimir a mulher que não detém renda) ou, de forma egoística, em decorrência da condição que a mulher exerce enquanto gestora econômica da família.

É necessário pactuar das verificações de Celmer (2010, pp. 74-75), para quem a aceitação social da violência contra mulher foi tão bem alicerçada culturalmente, que até as vítimas possuem dificuldade de reconhecer esta problemática como uma forma de violação dos seus direitos. A exemplo disto, existem muitas formas de violência psicológica e patrimonial permeando as relações conjugais e que não são dadas as devidas relevâncias, seja porque persiste a esperança de mudança do agressor, ou admite-se esta circunstância como uma condição a ser aturada, como um viés necessário para garantir a perpetuação da família e condições favoráveis para os filhos ${ }^{4}$. Desse modo, pode ser verificado que as relações sociais em âmbito doméstico e familiar são permeadas por escalonamentos de poder e produz uma subordinação que é aceita e, muitas vezes, acata até a violência física.

\section{A Lei Maria da Penha e a proteção jurídica feminina}

A edição da Lei $n^{\circ}$ 11.340/2006, também chamada de Lei Maria da Penha, em homenagem a Maria da Penha Maia Fernandes, vítima de duas tentativas de homicídio, pelo empenho empregado para ver o autor destes delitos, seu ex-marido, preso. Esta legislação deixa clara a necessidade de se repensar as relações de gênero, sobretudo no tocante a erradicação da violência. Assim, tal lei aponta desde seu art. $1^{\circ}$ a finalidade de coibir e prevenir a violência doméstica e familiar contra a mulher. Logo, simbolicamente, já detém desde seu nascedouro o semblante da luta feminina pela igualdade de gênero, sob o intento de proteger as mulheres em âmbito doméstico e familiar.

Um dos principais efeitos, que popularmente tornou essa lei conhecida, foi o endurecimento do trato penal sobre o assunto, sobretudo ao incrementar no código penal como circunstância agravante ao cometimento de crime "com abuso de autoridade ou prevalecendose de relações domésticas, de coabitação ou de hospitalidade, ou com violência contra a mulher (...)" (Art. 61, alínea "f", do Código Penal) e majorar a sanção penal do tipo de violência doméstica (Art. 129, § 9º além processualmente vetar a aplicação da Lei nº 9.099/1995 (Lei dos Juizados Especiais) para os casos de violência doméstica e familiar contra mulher, dentre

\footnotetext{
${ }^{4}$ No entanto, a verificação de reiterados atos de violência doméstica influencia diretamente na formação psicossocial das crianças e adolescentes, que passam a conviver com esta situação e tendem a reproduzi-la.
}

Barbarói, Santa Cruz do Sul, n. 56, p.<44-67>,jan./jun. 2020 
outras medidas.

A Secretaria de Políticas para as Mulheres da Presidência da República instituiu a Central de Atendimento à Mulher desde o ano de 2005, acontece que no transcorrer dos anos vem-se observando um aumento na quantidade de atendimentos, em 2014 realizou 485.105 registros ${ }^{5}$, correspondendo a uma média de 1.348 por dia, já em 2008 foram realizados 269.977 atendimentos ${ }^{6}$.

Note-se que a elevação da na quantidade de denúncias na referida central, de antemão leva a entender que a Lei Maria da Penha não tem galgado o resultado desejado na ceara penal, quanto ao interesse em desestimular vitimização de mulheres no Brasil, desta forma ela pode ser considerada um fracasso?

Para o Instituto de Pesquisa Econômica e Aplicada (IPEA, 2015a) não. Em estudo publicado em março de 2015, o qual versa sobre a efetividade da Lei Maria da Penha, onde foram utilizados diferentes técnicas, entre os quais uma análise econométrica com base no modelo de diferenças em diferenças, que basicamente se deteve em verificar a evolução da incidência de homicídios de homens e de mulheres, isolando-se as outras influências não relacionadas às questões de gênero, e atentando-se a diferença de crescimento entre os mesmos foi constatado que a Lei Maria da Penha conseguiu desestimular o aumento das taxas.

O IPEA considerou também que a Lei Maria da Penha afetou as vítimas e agressores em três circunstâncias:

\begin{abstract}
i) aumento do custo da pena para o agressor; ii) aumento do empoderamento e das condições de segurança para que a vítima pudesse denunciar; e iii) aperfeiçoamento dos mecanismos jurisdicionais, possibilitando ao sistema de justiça criminal que atendesse de forma mais efetiva os casos envolvendo violência doméstica. A conjunção dos dois últimos elementos seguiu no sentido de aumentar a probabilidade de condenação. Os três elementos somados fizeram aumentar o custo esperado da punição, com potenciais efeitos para dissuadir a violência doméstica. (IPEA, 2015b, p. 32)
\end{abstract}

Ainda assim, pode-se considerar que o aumento do número de denúncias pode ser causado pela maior visibilidade da questão e a não omissão das vítimas em denunciar, ou seja, a quebra do silêncio, o que deve ser considerado como um efeito extremamente positivo, sobretudo por ocasionar a superação de uma longa trajetória histórica e cultural de subordinação.

Além do mais, como bem observa Porto (2012, p. 19-20), no combate à violência

\footnotetext{
${ }^{5}$.Dados do Balanço 2014 da Central de Atendimento à Mulher (2015).

${ }^{6}$ Dados disponibilizados pela Central de Atendimento à Mulher - Ligue 180 - para o Observatório Brasil da Igualdade de Gênero. Disponível em: <http://www.observatoriodegenero.gov.br/eixo/indicadores/indicadoresnacionais/central-de-atendimento-a-mulher-ligue-180/dados-central-de-atendimento-2008>.
}

Barbarói, Santa Cruz do Sul, n. 56, p.<44-67>, jan./jun. 2020 
doméstica contra mulher, a sansão criminal não corresponde ao único instrumento de prevenção/erradicação deste problema, a Lei $n^{\circ}$ 11.340/2006 ainda causou repercussões em outras esferas do direito, dentre os quais administrativa, civil e trabalhista, inclusive a previsão de medidas de cunho assistencialista, como a disponibilização de acompanhamento multidisciplinar às vítimas e a possibilidade de ser inserida numa casa-abrigo.

Também é importante destacar que a própria definição legal estabelecida pela Lei Maria da Penha em seu art. $5^{\circ}$ indica que pode ser considerado como violência doméstica contra a mulher as ações que a prejudiquem não só fisicamente, mas também nos âmbitos psicológico, patrimonial, moral e sexual.

Mas não é apenas durante a ação do sujeito ativo que a violência se deflagra, em muitas situações o próprio sistema de justiça criminal que deveria mobilizar forças para garantir a erradicação ou, pelo menos, a minimização do problema, acaba facilitando a reprodução do problema, ou ainda os servidores públicos (policiais, médicos etc.), quando não for devidamente capacitado para entender as vicissitudes na questão, compreender os vieses socioeconômicos e culturais que permeiam a vitimização feminina, o que acaba por também reforçar a violência efetivada contra a mulher. E neste contexto que Porto informa:

É dentro dessa realidade de neutralização que a vítima sofre duas vitimizações: a primária decorrente do próprio crime que a vitimou, e a secundária resultante do modo como é maltratada pelo sistema legal, cujo formalismo, criptolinguagem, burocracia e até mesmo aviltamento por descrédito, tornam-na mais um objeto do que um legítimo sujeito de direitos. (PORTO, 2012, p. 51).

O prejulgamento estereotipado da conduta da mulher, vítima de violência doméstica, em muitos dos casos marcado pelo descrédito do teor da denúncia e, por conseguinte, a carência de medidas adequadas a sua proteção acaba dando margem para uma nova forma de vitimização: a impossibilidade de efetivar direitos constitucionalmente reconhecidos, o que também permite ao acusado cultivar um sentimento de impunidade e logo vê a possibilidade de realizar novas agressões com intensidade cada vez mais aviltante. Essa circunstância constitui uma formula desestimuladora de novas denúncias.

Assim, observa-se que outras formas de violência têm sido perceptíveis, contudo os mecanismos e a publicização da Lei Maria da Penha fizeram com que a mulher deixe de aceitar a sua vitimização para recorrer aos órgãos estatais em busca de segurança e justiça frente ao seu agravo.

Tal circunstância ganhou reforço após o julgamento da ADI n. ${ }^{\circ}$ 4424/2012 pelo Supremo Tribunal Federal, ocasião em que ficou estipulada a incondicionalidade da ação processual apta a jugar os casos de lesão corporal de natureza leve praticados com violência 
doméstica e familiar contra mulher (capitulado no art. 129, $\S 9^{\circ}$ do Código Penal), logo ainda que haja interesse da vítima em não prosseguir com a ação penal, esta deverá seguir o curso normalmente.

Nesta feita, salienta-se que a Lei Maria da Penha detém muitos aspectos positivos, dentre os quais, as previsões de:

- Criação dos Juizados ou Varas de Violência Doméstica e Familiar contra a Mulher para julgar os crimes, com atendimento multidisciplinar;

- Criação de novas Defensorias Públicas da Mulher;

- Medidas protetivas de urgência (suspensão do porte de armas, afastamento do agressor do lar, suspensão de visitas aos filhos etc.);

- Inclusão das mulheres em programas oficiais de assistência social;

- Atendimento à mulher em situação de violência por serviços articulados em rede, incluindo saúde, segurança, justiça, assistência social, educação, habitação e cultura, entre outros.

Destaque-se que a Lei $n^{\circ}$ 13.641/2018 alterou a Lei Maria da Pena acrescentando-lhe uma tipologia penal própria, qual seja o crime de Descumprimento de Medidas Protetivas de Urgência, atribuindo-o uma pena de detenção de 03 (três) meses a 02 (dois) anos, afiançável mediante arbitramento do juízo criminal.

Outrossim, deve-se reconhecer que a referida lei, acima de tudo, reconhece o "direito à diferença" que, conforme abordado por Comparato (2013, p. 302), implica na observação de uma relação desigual onde apenas ao possibilitar oportunidades em igual medida não é o suficiente, necessita-se antes de tudo do reconhecimento desta diferença e arcar com o dispêndio de condições para reequilibrar estas oportunidades, partindo-se sempre de uma ação positiva para restabelecer esse balanceamento, o que nada mais é do que um dos objetivos da mencionada norma. Neste interim, convém ressaltar as palavras de Comparato:

A discriminação contra a mulher se manifesta, também, pela reiterada e muito difundida denegação do direito à diferença, vale dizer, a recusa de reconhecimento e respeito dos dados biológicos e valores culturais, componentes do universo feminino. (COMPARATO, 2013, p. 302).

Corrobora ainda o autor supra referido, que o reconhecimento da diferença não implica necessariamente numa desigualdade, mas sim no acatamento das condições dos diferentes membros sociais, como elemento essencial para se construir, criar e elaborar uma união que é compreendida em sua complexidade e multiplicidade de fatores, crenças, sexos, ideologias, etc. o que é primordial para constituir o que se chama de "humanidade" (COMPARATO, 2013, p. 
$303)^{7}$.

Notadamente, as prescrições normativas instituem obrigatoriamente uma nova condição feminina, especificamente lhe dando autonomia social, econômica e jurídica para ir muito mais além, protegendo-a em diversos âmbitos de sua vida.

Outro aspecto positivo da referida lei foi tornar público as relações subjetivas até então circunscritas ao ambiente doméstico, dando voz as reclamações femininas, constituindo, por conseguinte, um espaço de libertação das amarras patriarcais, como também favorecendo o desenvolvimento de uma nova identidade da mulher, neste contexto o movimento feminista apesar de recente, exerceu importante papel$^{8}$.

Segundo as palavras de Porto (2012, p. 33), os crimes informados pela Lei Maria da Penha são caracterizados pela violência de gênero, cujas práticas especificadas em seu art. $7^{\circ}$, se assentam na finalidade delitiva desenvolvida a partir de um preconceito discriminatório contra a mulher. $\mathrm{O}$ atendimento das especificações contidas nos arts. $5^{\circ}$. e $7^{\circ}$. é suficiente para presumir a prática discriminatória.

Logo, ao tratar sobre a Lei Maria da Penha é importante reconhecê-la como um importante marco jurídico, pois a partir da mesma é iniciado de forma concreta um processo de ruptura histórica com as práticas de violência contra mulher, que se inicia com a implementação de mecanismos hábeis de confrontação ao ciclo de violência e subordinação onde estava inserida, encarando o problema sob um duplo viés, tanto aborda a repressão como, e principalmente, a prevenção.

Paralelamente a implementação e discussões sobre a referida lei, houve um verdadeiro processo de publicidade dos direitos femininos, o que vem possibilitando desenvolvimento de uma nova divisão de papéis sociais entre homens e mulheres, cada vez mais igualitários. Em outras palavras, a ideia de dignidade da pessoa humana, com toda a amplitude semântica conferida ao homem, começa a ser incorporada a mulher.

\footnotetext{
${ }^{7}$ Consoante relata Comparato (2013, p. 303) “ Ora, 'a humanidade', como bem disse Teilhard de Chardin, 'se enriquece pela união de suas diferenças'. Sem a existência de sexos, raças ou culturas diferentes, a humanidade perderia toda a sua capacidade evolutiva e criativa. Por isso, enquanto as desigualdades devem ser perpetuamente combatidas, as diferenças quando não contrárias à dignidade humana, hão de ser estimuladas e apoiadas".

${ }^{8}$ Mesmo antes da edição da Lei Maria da Penha, Neuma Aguiar (1997, p. 11) já informava que: "A última leva do movimento feminista no Brasil estabelece-se com a criação de grupos de consciência - uma proposta de autoreflexão, por intermédio da qual as mulheres rompem as barreiras da privacidade nas relações de gênero, quando trocam experiências com as demais participantes nessa organização. [...] Tornar público aquilo que fica oculto na subjetividade, ou recluso entre as quatro paredes da vida cotidiana, institui uma proposta de construção de uma nova identidade da mulher brasileira, não apenas como perspectiva individual - pertinente a cada participante da experiência - mas também como projeto coletivo, sendo esta uma das bases do momento social."
}

Barbarói, Santa Cruz do Sul, n. 56, p.<44-67>, jan./jun. 2020 


\section{0 serviço social em face da violência doméstica e familiar contra a mulher}

Conforme pode ser verificado nos capítulos anteriores, a violência doméstica e familiar contra a mulher é um problema muito antigo e que apenas muito recentemente vem recebendo a atenção jurídica necessária. Mesmo assim, por ser fruto de estereótipos social e culturalmente arraigados no cerne da sociedade brasileira, o reequilíbrio nas relações entre os sexos e consequente diminuição da incidência desta violência não é tarefa fácil de ser alcançada, de maneira que mesmo havendo legislações protecionistas dos direitos femininos, a exemplo da lei Maria da Penha, ainda assim pode-se observar uma frequente incidência deste problema.

Uma das maiores dificuldades relacionadas ao problema, é a detecção dos casos de violência doméstica contra a mulher que ainda é muito precária, perpassa por deficiências inclusive do auto reconhecimento da vitimização, o que faz da subnotificação uma questão que afeta as pesquisas e análises criminais acerca destes delitos, uma vez que, conforme apontam Cano et al (2012; p. 127):

Os registros policiais apresentam tradicionalmente o problema do subregistro, pois muitas vítimas deixam de registrar os crimes acontecidos por diversos motivos (falta de confiança no sistema de justiça criminal, medo da polícia etc.). Esse problema da subnotificação é um fenômeno mundial: na média dos 20 países pesquisados pelo UNICRI - Instituto Europeu de Criminologia da ONU - entre 1988 e 1992, cerca de $51 \%$ dos 10 crimes considerados deixaram de ser comunicados à polícia.

Outra preocupação é a forma como os primeiros órgãos procurados pelas mulheres recebem as vítimas de violência doméstica, muitas vezes até antes dos assistentes sociais serem informados sobre tais ocorrências. Assim, são os hospitais e clínicas que realizam o primeiro contato, isso implica em preocupações que extrapolam a segurança, como relatam Grabin et al (2006, p. 2568): “a violência doméstica, a mais comum das violências contra a mulher, deve ser detectada pelo profissional de saúde e encarada como questão de saúde pública”.

Tal proposição se deve porque na maioria dos casos as mulheres receiam em denunciar os agentes causadores (em boa parte das vezes, seus companheiros), tendo como o primeiro serviço público a ser procurado a assistência médica e nem sempre, os casos são devidamente detectados, constituindo uma cifra negra, que impossibilita a atuação do profissional de serviço social, dificultando, deste modo, um atendimento adequado a complexidade do problema.

$\mathrm{Na}$ maioria dos casos, este tipo de violência é realizado por pessoas que gravitam ao redor da vítima e gozam de certa intimidade, vivendo inclusive sob o mesmo teto, é o que apontam Grabin et al (2006, p. 2568) ao descreverem os agressores como sendo "em maioria os maridos, pais ou filhos, seguidos por namorados e ex-namorados, e finalmente conhecidos ou vizinhos", o que faz com que a violência dentro da própria casa seja uma das grandes Barbarói, Santa Cruz do Sul, n. 56, p.<44-67>,jan./jun. 2020 
responsáveis por uma série de delitos e, em grande parte dos casos, são estes mesmos que irão prestar socorro às vítimas até o hospital.

Ao verificar as pesquisas direcionadas a violência doméstica, Narvaz e Koller (2006) destacam que cerca de um quarto das brasileiras já foi vitimada, de modo que a cada quatro minutos uma mulher é agredida e que, em mais da metade das vezes, o responsável é o próprio marido ou companheiro ${ }^{9}$

Dessa maneira, verifica-se que a violência doméstica contra mulheres alcança níveis alarmantes e está fortemente enraizada nas relações sociais. Ademais, a detecção, repressão e prevenção dos delitos provenientes desta violência são difíceis de serem realizados sem a colaboração da vítima, familiares ou vizinhos e, sobretudo, de uma intervenção adequada do assistente social, o que acaba apenas por inviabilizar as prescrições assistenciais prevista na lei e fomentar um sentimento de impunidade dos agressores.

O receio de denunciar as práticas de violência configura uma das principais problemáticas a elaboração de ações ou estratégias estatais de combate, além disso Narvaz e Koller (2006, p. 9) destacam que o silêncio feminino tem outras motivações, dentre as quais o interesse em manter a família unida, a dependência financeira do parceiro, falta de apoio da família e da comunidade, o medo e insegurança proporcionados por ameaças e violência psicológica de seu algoz ${ }^{10}$

Conforme relatado por Cerqueira, Barbosa e Ângelo (2001, p. 39), as mulheres vitimadas possuem o seguinte perfil:

- tem baixa autoestima;

- acredita em todos os mitos a respeito dos relacionamentos violentos;

- é tradicionalista em relação ao lar, acreditando firmemente na unidade familiar e no estereótipo do papel sexual prescrito às mulheres;

- têm sentimento de culpa, embora negue o medo e a raiva que sente;

\footnotetext{
${ }^{9} \mathrm{Na}$ América Latina, a violência doméstica incide entre $25 \%$ e 50\% das mulheres. No Brasil, $23 \%$ das mulheres brasileiras estão sujeitas à violência doméstica; a cada 4 minutos, uma mulher é agredida em seu próprio lar por uma pessoa com quem mantém relação de afeto; $70 \%$ dos crimes contra a mulher acontecem dentro de casa e o agressor é o próprio marido ou companheiro; mais de $40 \%$ das violências resultam em lesões corporais graves decorrentes de socos, tapas, chutes, amarramentos, queimaduras, espancamentos e estrangulamentos. Outros estudos (Rede Saúde, 2001) apontam ainda que 11\% das brasileiras com 15 anos de idade ou mais já foram vítimas de espancamento. O levantamento encontrou que uma em cada cinco mulheres foi agredida pelo menos uma vez em suas vidas. A pesquisa mostra que o marido ou companheiro é responsável por $56 \%$ dos espancamentos, $53 \%$ das ameaças com armas e 70\% da destruição dos bens (NARVAZ; KOLLER, 2006, p. 8).

${ }^{10}$ Conforme exposição de Regina Célia A. S. Barbosa (2014) para Faculdade dos Guararapes, a violência contra mulher, em face de uma série de fatores como a dependência emocional, econômica, receio de retaliações, entre outros, muitas vezes não é noticiada aos órgãos públicos, o que favorece o desenvolvimento do sentimento de impunidade do agressor, tornando-a um evento reiteradamente perceptível em meio a relação conjugal, mas crescentemente prejudicial à mulher.
}

Barbarói, Santa Cruz do Sul, n. 56, p.<44-67>,jan./jun. 2020 
- revela uma aparência passiva para o mundo, mas possui bastante força para manipular o seu ambiente a fim de evitar o abuso subsequente e o risco de ser morta;

- $\quad$ expressa reações graves de estresse, com queixas psicofisiológicas;

- usa o sexo como um modo de estabelecer a intimidade; e

- acredita que ninguém será capaz de ajudá-la a solucionar sua dificuldade exceto ela mesma.

A vitimização das mulheres nas relações domésticas, essencialmente por seus parceiros, demonstra a desestabilização na formulação estrutural das condições de paridade familiar entre mulheres e homens, sedimentada em práticas de discriminação e subordinação do gênero feminino.

Pensar em minimizar as práticas de abuso contra mulher dentro das relações domésticas, cujo cerne é regado por intimidade e privacidade, é primeiramente imaginar em intervenções particularizadas, acompanhadas por um assistente social com habilidade para realizar a escuta, detecção e intervenção perante o caso, realizando os devidos encaminhamentos no intento de dar cumprimento às normas estatuídas pela Lei Maria da Penha e direitos fundamentais femininos.

Atualmente a lei no 11.340/2006 (Lei Maria da Penha) prevê normativamente condições direcionadas a reprimir os casos de violência contra a mulher, como também institui uma série de medidas protetivas e de atendimento as mulheres vitimizadas, dentre os quais se podem citar o atendimento por equipe multidisciplinar, assistência jurídica, as delegacias especializadas de atendimento à mulher, casas-abrigos, mas não para por aí, cria mecanismos de ressocialização dos agressores, através dos centros de educação e de reabilitação para agressores.

Como aponta Saffioti (2012), a violência doméstica é um problema de ordem social, logo necessita ser tratado como tal, desse modo é necessário criar um paradigma sociocultural de superação aos estereótipos e preconceitos que outrora mancharam o pudor feminino com ódio, sangue e violência, portanto é imprescindível a atuação do assistente social, não apenas para a detecção, mas também para formular um processo atendimento pautado na conscientização das vítimas sobre seu direito a condições igualitário de convivência e, assegurar, através dos pertinentes encaminhamentos, a efetivação/garantia dos direitos fundamentais da mulher.

Ao considerar as condições de execução das práticas de violência doméstica contra a mulher divulgados midiaticamente, pode-se constatar que no âmago destas ações está a relativização da dignidade feminina, uma circunstância que extrapola as relações privadas e 
deve ganhar interesse público, não só pela percepção de uma constante incidência, mas também pelos reflexos diretos, como o aumento de gastos públicos com saúde, impacto econômico sobre o mercado de trabalho, sobre as relações familiares, especialmente quanto a vulnerabilidade à qual os filhos acabam sendo submetidos, entre outros.

Nos hospitais, surgem com frequência circunstâncias sociais adversas que, na opinião de médicos e enfermeiros, justificam a intervenção do assistente social, uma delas é a constatação da vitimização das mulheres por violência doméstica e familiar e o receito destas em procurar ajuda ou denunciar. Dessa forma, a fragilização das vítimas pelos efeitos da violência, sobretudo quando os responsáveis são seus próprios companheiros (o que ocorre na maior parte das vezes) inviabiliza a exposição dos fatos e, por conseguinte, a solicitação de apoio dos órgãos de segurança pública e o atendimento adequado.

Neste contexto, o Assistente Social exerce um papel imprescindível, não apenas quanto a orientação das vítimas, mas também na articulação dos serviços essenciais para seu atendimento e responsabilização dos seus atores. Desta maneira, a lei ${ }^{\circ}$ 8.662/93 traz em seu âmago a missão do profissional de serviço social como o compromisso de defender e garantir os direitos sociais da população, intencionando o fortalecimento da democracia.

A violência doméstica e familiar contra mulher também se concretiza através da atuação ou omissão política, em razão da não intervenção de serviços públicos essenciais, da dificuldade em reduzir deficiências socioeconômicas e educacionais e da carência de ações de inclusão e de incentivo ao desenvolvimento da igualdade de gênero de forma ampla. Notavelmente, verifica-se que a imprensa também influi diretamente para o desenvolvimento desta violência, sobretudo por meio da exploração de corpo feminino, como ocorre nos anúncios publicitários, mas também não se pode perder de vista a exploração sem limites de ocorrências policiais em que as mulheres estejam sob a condição de vítimas (AZEVEDO; GARCIA, 2011, p. 03).

Em pesquisa realizada por Blay (2003, p. 92-93) em diversificadas fontes, a escritora pode constatar uma transformação do conteúdo da mídia que na década de 1980 as vítimas eram apresentadas como causadoras de sua própria morte, já no início do século XX os eventos passam a ser noticiados com relativa neutralidade e cercado de críticas em torno da eficiência da lei. Não se pode olvidar ainda que este é um processo em desenvolvimento uma que a exploração da violência ainda é muito evidente.

Os programas televisivos, que dramatizam os crimes passionais, estupros seguidos de morte, incesto, trazem uma dupla mensagem: de um lado acusam o criminoso mas, ao mesmo tempo, romantizam esse tipo de crime. Esses veículos tendem a reproduzir a antiga versão de que a "vítima é responsável por sua morte" e, muitas vezes, ao reiterarem imagens e reconstituições dos supostos fatos exaltam os crimes. (BLAY, 2003, p. 93)

Barbarói, Santa Cruz do Sul, n. 56, p.<44-67>,jan./jun. 2020 
Côrtes, Luciano e Dias (2012, p. 137-138) chamam a atenção para a necessidade de uma política de informação na área de gênero para não só diagnosticar a situação social das mulheres, mas também indicar medidas aptas a superação das desigualdades verificáveis em distintos espaços sociais. No entanto, esta não é uma atividade tão simples de ser realizada em razão da dispersão dos dados, o que acarreta sempre uma imprecisão. Um dos primeiros pontos, informa os autores, é a falta de uniformização e de um sistema integrado de registros de ocorrências, outrossim ainda persiste a carência de percepção de muitos profissionais para a sistematização da coleta de dados, dificultando o monitoramento e a investigação do tema.

O modo como as informações são relevadas a uma sub-preocupação social e estatal acaba por agravar as formas de violência verificáveis, por dissipar um sentimento de impunidade, de inoperância das estruturas do sistema de justiça criminal para lidar com as demandas e de precariedade dos serviços de assistência e inserção social, conforme trata Côrtes, Luciano, Dias (2012, p. 138):

Assim, a informação configura-se como um elemento basilar no processo de mudança dessas estruturas de conhecimento, tais como a naturalização e a complacência à violência e a visão estereotipada sobre a conduta das mulheres, uma vez que gera novas formas de compreensão, ação e intervenção dos sujeitos sociais [...].

Os autores ainda prosseguem informando que “[...] a gestão da informação é fundamental para se aperfeiçoar o planejamento de ações e tomar decisões condizentes com as necessidades informacionais das mulheres" (CÔRTES, LUCIANO, DIAS, 2012, p. 139). Isso implica dizer que a forma como for gerida a informação dentro de um determinado contexto espaço-temporal poderá proporcionar o desenvolvimento ou desestímulo do processo de inclusão/exclusão de sujeitos, valorização das suas capacidades físicas ou cognitivas, trazendo reflexos não apenas para o campo subjetivo, mas em toda a dinâmica social, perpassando pelas estruturas econômica, política, cultural e, principalmente, jurídica.

Diante destas circunstâncias, a forma de administrar os recursos informacionais pode abrir ou fechar espaços direcionados para o gozo e exercício de direitos em diversos âmbitos. Logo, tratar de forma adequada as informações, pesquisas e o modo de divulgação de medidas preventivas contra a violência doméstica contra mulher, constitui um recurso direto de intervenção social e favorecimento direto a subversão das causas do problema e ressignificação das disposições deterministas e naturalizantes que o fundamentam (CÔRTES, LUCIANO, DIAS, 2012, p. 139), as quais foram se cristalizando em decorrência de uma histórica dominação masculina e subjugação dos interesses femininos, principalmente no espaço doméstico. 
Levando em consideração a importância do assistente social também relacionado ao serviço de saúde, observa-se seu necessário compromisso na escuta e, consequentemente, para orientar e apoiar as mulheres vítimas de violência, como também articular as políticas públicas necessárias a superação dos efeitos da vitimização.

\footnotetext{
Os direitos sociais refletem conquistas do movimento democrático e das lutas sociais em operações políticas complexas, o que nos leva a reafirmar que o papel do assistente social é o de defender tais direitos e participar no processo de ampliação dos mesmos, buscar através de estratégias de ação, desenvolver nos diversos fatores sociais a capacidade de problematizar suas reais necessidades e inseri-las nas arenas de decisões políticas (ESTEVAM; MAGRIN, 2005, p. 50).
}

Portanto, a intervenção do assistente social, neste contexto, pressupõe um contato direto com as mulheres vítimas de violência, orientando-as e oferecendo o apoio indispensável, além do auxílio que é disponibilizado pelas instituições de saúde, promovendo a inserção da mulher nos programas sociais regionais, a fim de minimizar os efeitos da vitimização. Neste contexto, pode-se destacar que o encaminhamento ao Centre de Referência Especializado de Assistência Social (CREAS), que detém entre suas funções a orientação sócio-familiar, atendimento psicossocial, assistência jurídica, além de também prestar orientação e informações sobre a defesa dos seus direitos, notificação do caso a Delegacia Especializada de Atendimento à Mulher (DEAM), Promotoria, Polícia Militar etc.

Deste modo, a relevância deste trabalho estaciona na necessidade de enfatizar e refletir sobre o papel do assistente social para fins de detecção e realização das demais medidas pertinentes para salvaguardar a dignidade da mulher vitimada.

\section{Considerações finais}

Conforme constatou-se no transcorrer deste trabalho, a cultura patriarcalista se projetou no decorrer da história e foi incorporada ao Brasil desde a chegada das primeiras caravelas. A princípio, a nítida divisão de papéis sociais marcadas pelas diferenças de sexo apesar de, no decorrer do tempo vem sofrendo modificações em razão das transformações socioeconômicas e jurídicas nacionais, sobretudo pelo reconhecimento dos direitos femininos, mas não tem sido fundamentalmente capazes de solapar a incidência da violência doméstica e familiar contra a mulher.

Mesmo assim, não se pode deixar de reconhecer que a reivindicação por acesso a direitos pelos movimentos sociais e a forte pressão dos grupos feministas iniciados na década de 1970 confluíram na criação de uma nova ordem constitucional, com prescrições normativas dirigidas a promoção da igualdade material entre os sexos e, uma consequente, reequilíbrio da relação de poder sexista existente em âmbito doméstico. 
Esta circunstância ganha impulso a partir da edição, principalmente, da Lei 11.340/2006 (Lei Maria da Penha) e Lei 13.104/2015 (Lei do Feminicídio), as quais dão um trato penal especial das formas de vitimização feminina, sobretudo no tocante a responsabilização dos agressores, vindo a representar a conformação de um direito a diferença, que nada mais é que o reconhecimento jurídico das discrepâncias nas relações entre gêneros e aplicação de medidas voltadas à sopesar o lado mais frágil desta relação em face da histórica opressão sofrida.

Mas é importante ressaltar que os contributos da Lei Maria da Penha não se resumem às medidas de cunho penal, a técnica legislativa que lhe revestiu também previu normas de cunho administrativo, civil e trabalhista, voltados a assegurar uma ampla proteção feminina, inclusive o atendimento por profissionais especializados e por equipe multidisciplinar, inclusive de assistência social, para fins de inserção as vítimas nos programas governamentais assistenciais e acolhimento pela rede de atendimento à mulher em situação de vulnerabilidade.

Mesmo depois de mais de dez anos da edição da Lei Maria da Penha, pode-se dizer que seus resultados, apesar de positivos, ainda são limitados pela falta de adequação estatal para lidar com o tipo de demanda que esta legislação propõe, sobretudo pela carência de infraestrutura, além da ainda existente precária orientação popular sobre o tema.

Como reflexo destas carências, observa-se, em alguns casos, a falta de preparo de muitos profissionais (de saúde, segurança pública...) para lidar com a questão, especificamente para reconhecer/diagnosticar a vitimização feminina, circunstância que, muitas vezes, também afeta a própria mulher-vítima. Por questões de ordem cultural, muitas mulheres não são capazes de reconhecer que foram violentadas, isso também causa prejuízos ao tratamento e encaminhamento aos serviços assistenciais essenciais às vítimas.

Neste contexto deve sobressair o protagonismo do assistente social notavelmente dirigido para a escuta e orientação das vítimas e dos profissionais envolvidos na rede de atendimento (policiais, médicos, enfermeiros etc.) sobre as vicissitudes e complexidade da violência doméstica e familiar contra a mulher e pelo acompanhamento de todas as vítimas para serviços como CREAS, atendimento médico e psicossocial especializado, Ministério Público, DEAM, Polícia Militar, como circunstância basilar para o enfrentamento a vitimização, perpassando pela mobilização da rede de atendimento para fins de acolhimento e minimização dos efeitos ocasionados pela violência e responsabilização do agressor. 


\title{
THE SOCIAL ASSISTANT AND CARE FOR WOMEN VICTIMS OF DOMESTIC AND FAMILY VIOLENCE
}

\begin{abstract}
This work deals with domestic and family violence against women, starting from the question about how the social worker should act in the face of occurrences of this nature. The specific objectives are to appreciate the complexity and characteristics of the theme and to verify the importance of this professional in these types of cases. From the methodological point of view, the techniques of documentary and bibliographic research were used, as skillful instruments to enable a deductive approach, when the collected bibliographic review should support the analyzes to stipulate the conditions of exercise of the social assistance professional in the face of problem handled. In view of the precarious knowledge about the peculiarities of domestic violence, many victims have difficulties in recognizing their victimization, causing deficiency in the detection by the professionals involved in the care (police, doctors, etc.), which can only be supplied by qualified listening and intervention by the assistant social, through guidance on rights and guarantees for the physical, psychological, patrimonial, moral and sexual integrity of women in a vulnerable state, articulation of the service network and appropriate referrals.
\end{abstract}

Keywords: Woman. Violence. Social Worker. Rights.

\section{REFERÊNCIAS}

AGUIAR, Neuma (org.). Gênero e ciências humanas: desafios às ciências desde a perspectiva das mulheres. Rio de Janeiro: Record; Rosa dos Tempos, 1997.

AZEVEDO, Sandra Raquew dos Santos; GARCÍA, Loreley Gomes. Violência contra as mulheres na agenda midiática. Espaço do Currículo, v.4, n.1, p.3-21, mar./ set. 2011.

\section{BARBOSA, Regina Célia A. S. Políticas Públicas para o combate da Violência de}

Gênero: experiência brasileira da Lei Maria da Penha. Jaboatão dos Guararapes: Faculdade dos Guararapes, Disponível em:

https://my.laureate.net/Faculty/webinars/Documents/2013Junio_WEBINAR_FG_Politicas\%2 0P\%C3\%BAblicas\%20para\%20o\%20combate\%20da\%20viol\%C3\%AAncia\%20de\%20g\%C 3\%AAnero.pdf . Acesso em 18 jul. 2017.

BLAY, E. A et al. Violência contra a mulher e políticas públicas. Estudos avançados, São Paulo, v. 17, n. 49, p. 87 - 98, 2003. Disponível em:

http://www.scielo.br/pdf/ea/v17n49/18398.pdf . Acesso em 02 set. 2017.

BOURDIEU, Pierre. La dominación masculina. Traducción de Joaquín Jordá. Barcelona: Anagrama, 2000.

BRASIL. Câmara dos Deputados. Legislação da mulher. 4. ed. Brasília: Câmara dos Deputados; Edições Câmara, 2011.

Constituição (1988). Constituição da República Federativa do Brasil. Brasília, DF:

Senado Federal, 1988. Disponível em:

http://www.planalto.gov.br/ccivil_03/constituicao/constituicao.htm . Acesso em 02 set. 2017.

Decreto-Lei n ${ }^{\circ}$ 2.848, de 07 de dezembro de 1940. Código Penal. Diário Oficial [da]

República Federativa do Brasil, Brasília, DF, 8 dez. 1940. Disponível em: 
http://www.planalto.gov.br/ccivil_03/decreto-lei/Del2848compilado.htm . Acesso em 02 set. 2017.

Lei $n^{\circ}$ 8.662, de 7 de junho de 1993. Dispõe sobre a profissão de Assistente Social e dá outras providências. Diário Oficial [da] República Federativa do Brasil, Brasília, DF, 8 jun. 1993. Disponível em: http://www.planalto.gov.br/ccivil_03/Leis/L8662.htm . Acesso em 01 set. 2017.

Lei $n^{\circ}$ 9.099, de 26 de setembro de 1995. Dispõe sobre os Juizados Especiais Cíveis e Criminais e dá outras providências. Diário Oficial [da] República Federativa do Brasil, Brasília, DF, 27 set. 1995. Disponível em: http://www.planalto.gov.br/ccivil_03/Leis/L9099.htm . Acesso em 03 set. 2017.

Lei $\mathrm{n}^{\circ} 11.340$, de 07 de agosto de 2006. Cria mecanismos para coibir a violência doméstica e familiar contra a mulher, nos termos do $\S 8^{\circ}$ do art. 226 da Constituição Federal, da Convenção sobre a Eliminação de Todas as Formas de Discriminação contra as Mulheres e da Convenção Interamericana para Prevenir, Punir e Erradicar a Violência contra a Mulher; dispõe sobre a criação dos Juizados de Violência Doméstica e Familiar contra a Mulher; altera o Código de Processo Penal, o Código Penal e a Lei de Execução Penal; e dá outras providências. Diário Oficial [da] República Federativa do Brasil, Brasília, DF, 08 ago. 2006. Disponível em: http://www.planalto.gov.br/ccivil_03/_ato2004-2006/2006/lei/111340.htm . Acesso em 02 set. 2017.

. Lei ${ }^{\circ} 13.104$, de 09 de março de 2015. Altera o art. 121 do Decreto-Lei no 2.848 , de 7 de dezembro de 1940 - Código Penal, para prever o feminicídio como circunstância qualificadora do crime de homicídio, e o art. $1^{\circ}$ da Lei n ${ }^{\circ} 8.072$, de 25 de julho de 1990, para incluir o feminicídio no rol dos crimes hediondos. Diário Oficial [da] República Federativa do Brasil, Brasília, DF, 10 mar. 2015. Disponível em: http://www.planalto.gov.br/ccivil_03/_Ato2015-2018/2015/Lei/L13104.htm . Acesso em 02 set. 2017.

Lei $\mathrm{n}^{\circ} 13.641$, de 03 de abril de 2018. Altera a Lei $\mathrm{n}^{\circ} 11.340$, de 7 de agosto de 2006 (Lei Maria da Penha), para tipificar o crime de descumprimento de medidas protetivas de urgência. Diário Oficial [da] República Federativa do Brasil, Brasília, DF, 04 abr. 2018. Disponível em: http://www.planalto.gov.br/ccivil_03/_Ato20152018/2018/Lei/L13641.htm\#art2 . Acesso em 17 mar. 2020.

MINISTÉRIO DA SAÚDE. Secretaria de Vigilância em Saúde. Impacto da violência na saúde dos brasileiros. Brasília: Ministério da Saúde, 2005.

Observatório Brasil da Igualdade de Gênero. 2009 Disponível em:

http://www.observatoriodegenero.gov.br/eixo/indicadores/indicadores-nacionais/central-deatendimento-a-mulher-ligue-180/dados-central-de-atendimento-2008 . Acesso em 11 jul. 2015 .

Presidência da República. Secretaria de Política para as Mulheres. Central de Atendimento à Mulher. Balanço 2014. Brasília. 2015. Disponível em: http://www.spm.gov.br/central-deconteudos/publicacoes/publicacoes/2015/balanco180_2014-versaoweb.pdf . Acesso em 11 jul. 2015. 
Secretaria de Políticas para as Mulheres. Central de Atendimento à Mulher.

Disponível em: http://www.spm.gov.br/ouvidoria/central-de-atendimento-a-mulher . Acesso em 11 jul. 2015.

Secretaria de Políticas para as Mulheres. Dados da Central de Atendimentos à Mulher - Ligue 180. Relatório 2011 por Unidade Federativa. Atendimentos com denúncias. Disponível em: http://www.spm.gov.br/noticias/documentos-1/denuncias . Acesso em 11 jul. 2015.

Senado Federal. Comissão Parlamentar Mista de Inquérito. Relatório Final. Com a finalidade de investigar a situação da violência contra a mulher no Brasil e apurar denúncias de omissão por parte do poder público com relação à aplicação de instrumentos instituídos em lei para proteger as mulheres em situação de violência. Brasília: Senado Federal, 2013. Disponível em: http://www.senado.gov.br/atividade/materia/getPDF.asp?t=130748\&tp=1 . Acesso em 23 jun. 2014.

. Supremo Tribunal Federal. Ação Direta de Inconstitucionalidade 4.424. A ação penal relativa a lesão corporal resultante de violência doméstica contra a mulher é pública incondicionada. Brasília, 2012. Disponível em: http://www.compromissoeatitude.org.br/wpcontent/uploads/2012/07/ADI4424STF09022012.pdf . Acesso em: 13 jul. 2015.

CANO, Ignácio et al. Mapeamento da Criminalidade na Área Metropolitana do Rio de Janeiro. p. 123 - 175. Disponível no site: http://www.iets.org.br/biblioteca/Mapeamento_ da_criminalidade_na_area_metropolitana_do_RJ.pdf. Acesso em 02 set. 2017.

CELMER, Elisa Girotti. Violências contra a mulher baseada no gênero, ou a tentativa de nomear o inominável. In: ALMEIDA, Maria da Graça (Org.). A violência na sociedade contemporânea. Porto Alegre: EDIPUCRS, 2010.

CERQUEIRA, Carlos Magno Nazareth; BARBOSA Sérgio Antunes; ANGELO, Ubiratan de Oliveira. Distúrbios Civis: Controle e Uso da Força pela Polícia. Rio de janeiro: Freitas Bastos, 2001. (Coleção Polícia Amanhã; textos fundamentais de polícia; 4)

COMPARATO, Fábio Konder. A afirmação histórica dos direitos humanos. - 8. ed. - São Paulo: Saraiva, 2013.

CÔRTES, Gisele Rocha; LUCIANO, Maria Cristiana Félix; DIAS, Karla Cristina Oliveira. Informação no enfrentamento à violência contra mulheres: Centro de Referência da Mulher "Ednalva Bezerra": relato de experiência. Biblionline, João Pessoa, v. 8, n. esp. p.134-151, 2012. Disponível em:

http://www.biblionline.ufpb.br/ojs/index.php/biblio/article/download/14199/8105 . Acesso em 20 out. 2016.

DAY, Vivian Peres et al. Violência doméstica e suas diferentes manifestações. Revista Psiquiatr. RS, v. 25 (suplemento 1), p. 9-21, abr. 2003. Disponível em: http://www.scielo.br/pdf/rprs/v25s1/a03v25s1 . Acesso em 02 set. 2017.

ESTEVAM, Érika Fabiana Brugnola; MAGRI, Grazielle Pereira. Assistente Social: Um garantidor de direitos? Monografia (Bacharelado em Serviço Social). Presidente Prudente: 
FACULDADES INTEGRADAS “ANTÔNIO EUFRÁSIO DE TOLEDO”, 2005. Disponível em: http://intertemas.unitoledo.br/revista/index.php/Juridica/article/view/418/412 . Acesso em 20 out. 2016.

FÓRUM BRASILEIRO DE SEGURANÇA PÚBLICA (FBSP); DATAFOLHA. Visível e invisível: a vitimização de mulheres no Brasil: Infográficos. 2019. Disponível em: http://www.forumseguranca.org.br/wp-content/uploads/2019/02/Infogra\%CC\%81ficovis\%C3\%ADvel-e-invis\%C3\%ADvel-2.pdf . Acesso em 20 abr. 2020.

GOMES, Romeu. A Dimensão Simbólica da Violência de Gênero: uma discussão introdutória.

Athenea Digital, n. 14, 2008, pp. 237-243. Disponível em:

http://psicologiasocial.uab.es/athenea/index.php/atheneaDigital/article/view/520 . Acesso em 05 set. 2017.

GUIMARÃES, Isaac Sabbá. Lei Maria da Penha: aspectos criminológicos de Política Criminal e do Procedimento Penal. 2. ed. rev. e atual. Curitiba: Juruá, 2011.

INSTITUTO DE PESQUISA ECONÔMICA APLICADA (IPEA). Pesquisa avalia a efetividade da Lei Maria da Penha. 2015a. Disponível em:

http://www.ipea.gov.br/portal/index.php?option=com_content $\& v i e w=\operatorname{article} \& i d=24610$. Acesso em: 22 jul. 2016.

Texto para discussão no 2048. Avaliando a efetividade da Lei Maria da Penha. Brasília: Rio de Janeiro: Ipea, 2015b. Disponível em: http://www.ipea.gov.br/portal/images/stories/PDFs/TDs/td_2048.pdf . Acesso em 22 jul. 2016.

; FÓRUM BRASILEIRO DE SEGURANÇA PÚBLICA (FBSP) (Org.). Atlas da Violência 2019. Brasília: Rio de Janeiro: São Paulo: Instituto de Pesquisa Econômica Aplicada; Fórum Brasileiro de Segurança Pública, 2019. Disponível em:

http://www.ipea.gov.br/atlasviolencia/download/19/atlas-da-violencia-2019 . Acesso em 20 abr. 2020.

MARCONI, Marina de Andrade; LAKATOS, Eva Maria. Fundamentos de Metodologia Científica. 5. ed. São Paulo: Atlas, 2003.

NARVAZ, Martha Giudice; KOLLER, Sílvia Helena. Mulheres vítimas de violência doméstica: Compreendendo subjetividades assujeitadas. PSICO, Porto Alegre, PUCRS, v. 37, n. 1, p. 7 - 13, jan./ abr. 2006. Disponível no site:

http://revistaseletronicas.pucrs.br/ojs/index.php/revistapsico/article/viewFile/1405/1105 .

Acesso em 05 set. 2017.

PORTO, Pedro Rui da Fontoura. Violência doméstica e familiar contra a mulher: Lei 11.340/06: análise crítica e sistêmica. 2. ed. rev. e atual. Porto Alegre: Livraria do Advogado Editora, 2012.

SAFFIOTI, Heleieth I. B. Violência doméstica: questão de polícia e da sociedade. Disponível no site:

http://www.pagu.unicamp.br/sites/www.pagu.unicamp.br/files/colenc.01.a06.pdf . Acesso em Barbarói, Santa Cruz do Sul, n. 56, p.<44-67>,jan./jun. 2020 
05 set. 2017.

SOUZA, Sérgio Ricardo. Comentários à lei de combate à violência contra mulher. 3. ed. Curitiba: Juruá, 2009.

Data de recebimento: $17 / 03 / 2020$

Data de aceite: $21 / 05 / 2020$

\section{Sobre os autores:}

Allan Jones Andreza Silva é doutorando em Ciências Jurídicas pelo PPGCJ (UFPB), Mestre em Ciências Jurídicas (UFPB), Especialista em Direitos Fundamentais e Democracia (UEPB), Bacharel em Direito (UEPB), Bacharel em Segurança Pública (PMPB), Docente da PMPB, Capacitado em Análise Criminal (SENASP). Endereço Eletrônico: allanjonesgba@hotmail.com

Daniele de Araújo Nogueira é Bacharel em Serviço Social (UNOPAR), capacitada em prevenção ao uso de drogas (UFSC). Endereço Eletrônico: danny-gba@hotmail.com 